\section{Limites e possibilidades do Partido Fardado}

Oliveiros S. FERREIRA. Elos partidos: uma nova visão do poder militar no Brasil. São Paulo, Harbra, 2007. 594 páginas.

\section{Marco Aurélio Nogueira}

Há duas maneiras consideradas típicas de se ler o Brasil. Uma, a dos que se costuma chamar de intérpretes, caracteriza-se pelo tom ensaísta e pelas construções abrangentes, que visam a reter tendências e modos de ser, valendo-se quase sempre de uma perspectiva historicista e de boa dose de erudição. Outra, a dos que se definem como cientistas sociais, distingue-se pelo foco concentrado, pela busca do detalhe exemplar, pelo estudo de caso, pondo-se quase sempre de um ponto de vista tido como metodologicamente correto, a partir do qual se aposta na possibilidade de controles finos, rigorosos, empiricamente respaldados.

Independentemente do quanto se atribua de valor a esta dicotomia, aqui, como em muitas outras situações, Virtus consistit in medio: a verdade está no meio. Não há motivos plausíveis suficientes para que se prolongue a distância entre os dois ângulos e estilos de interpretação. Não se trata somente de preferência ou treinamento especializado, mas de exigência do real, que, em sua complexidade e em seu constante evoluir, impõe, aos estudiosos, tanto uma boa dose de modéstia e humildade como a disposição determinada de ir além de alguns amontoados criteriosos de dados e provas. Conhecer não é simplesmente tomar este ou aquele pedaço de algo tido como relevante e submetê-lo a exercícios sistemáticos de evidenciação. É antes de tudo alcançar uma visão de conjunto que articule segmentos, detalhes, trajetórias e fatos num todo coerente, ainda que dinâmico e contraditório. Sem isso, o conhecimento não se traduz em recurso social e não tem como almejar ser útil às pessoas comuns ou à comunidade política de homens e mulheres.

De resto, as ciências humanas estão repletas de intelectuais que trafegam com desenvoltura por ambos os caminhos, sem se deixar paralisar por hipotéticas contraposições entre eles. São pensadores que não amaldiçoam as grandes narrativas nem torcem o nariz para o detalhe significativo, que não temem o rigor dos fatos mas não se inti- midam diante da grandiosidade da história, e que seguem em frente indiferentes à última moda, às manias e idiossincrasias acadêmicas, comprometidos exclusivamente em fazer com que os fatos falem, revelem, ensinem algo. Que interpretam, em suma, mas não descuidam do trabalho duro, da pesquisa exaustiva, criteriosa, muitas vezes respaldada em fontes diretas, entrevistas, recortes de jornais, observação obsessiva de fatos e personagens.

Tudo isso pode ser dito para convidar os cientistas sociais a se debruçar com a devida atenção sobre o novo livro de Oliveiros S. Ferreira, Elos partidos, que, como todos os seus anteriores, foi publicado à margem do mainstream, sem pompa, circunstância ou badalações, e que desvenda um panorama largo, impelindo-nos para uma verdadeira viagem às entranhas da história.

Oliveiros Ferreira reúne o erudito ao analista político minucioso, os grandes quadros interpretativos aos fatos cotidianos muitas vezes soterrados ou apagados pela valorização unilateral dos processos estruturais. A paixão do pesquisador acadêmico completa-se com a argúcia do jornalista profissional, conformando uma figura rara de intelectual público. Não é por acaso, ou por afetação, que em sua concepção se cruzam influências e orientações recebidas de autores tão díspares quanto Durkheim e Gramsci, Weber e Trotsky, Unamuno e Marx, Ortega y Gasset e Clausewitz. É que sua estrutura de pensamento está de certa maneira acima de filiações imediatas, como se repousasse em uma zona livre, na qual se aceita tudo aquilo que favorece a argumentação. Com isso, Oliveiros fornece a seus leitores um texto denso, vez ou outra tortuoso, repleto de referências literárias e metáforas eloqüentes, num estilo que já foi visto como "elíptico, às vezes alusivo, outras quase esotérico" (Gildo M. Brandão, na apresentação do livro). Pode-se lê-lo com certo incômodo ou inquietação, mas o exercício sempre exigirá o fôlego preso, tamanha a habilidade do autor em envolver o leitor e surpreendêlo com conclusões inusitadas, heterodoxas, provocativas, invariavelmente esclarecedoras, que forçam à reflexão e à revisão.

Talvez por isso mesmo, Oliveiros Ferreira não pode ser visto como autor de "achados" ou preso ao dernier crí, às idéias canônicas, aos consensos fáceis. Sequer faz questão de se renovar a cada livro ou artigo. Prefere insistir em sua vigorosa interpretação do Brasil e na reiteração das cláusulas pétreas 
de sua sociologia política - o Estado, a necessidade da ordem, o poder como posse de almas, mentes e recursos materiais, a dimensão psicossocial dos fatos políticos, o valor da organização e da iniciativa organizada, o projeto nacional.

Oliveiros repisa este caminho em Elos partidos, no qual sintetiza - reúne e articula em nível superior, justificando o subtítulo "uma nova visão do poder militar no Brasil" - sua teoria política e sua interpretação do Brasil. A hipótese principal desta interpretação aflora a todo instante, insidiosa e sedutora: por não terem podido se organizar com autonomia e coerência, conscientes de si e para si, as classes sociais brasileiras transferiram ao Estado as tarefas típicas que lhes deveriam caber - a organização do país e dos consensos sociais, a construção da hegemonia, a modelagem da administração pública, o planejamento da industrialização e do desenvolvimento, a defesa da soberania, em suma, tudo aquilo que poderia configurar um projeto nacional.

Mas o Estado não se move por força de leis abstratas e aparatos impessoais. Necessita de sujeitos que lhe dêem vertebração, materialidade e orientação de sentido. $\mathrm{Na}$ ausência das classes e de uma "consciência nacional de classe", abriu-se um vazio político, ideológico e operacional, causa das muitas irregularidades e turbulências do processo histórico, bem como de um pesadelo permanente: o da ditadura, das guinadas autoritárias, da democracia espasmódica e imperfeita, da hipertrofia dos vértices em detrimento das bases. Tais desdobramentos ajudarão a que se fixe, nas estruturas histórico-sociais, uma grave disjunção entre Estado e sociedade. E darão impulso à generalização de uma cultura política pouco republicana e pouco permeável à democracia.

Em política, porém, "vazios" não ficam sem ocupação. No decorrer da história brasileira, uma parte da estrutura estatal - a mais bem organizada - terminaria por agir com maior desenvoltura e protagonismo. $\mathrm{Na}$ medida em que o país foi se constituindo e fixando um padrão, os "Militares" tornam-se, juntamente com o "Estado" e a "Federação", os verdadeiros sujeitos de ação. E dado que são, diferentemente do "Estado" e da "Federação", um corpo que se move por critérios de maior coerência, disciplina e coesão, inspirado bem mais pelo princípio da Honra que da Lei (pp. 53-54), bem como por um insulamento que os protege e fortalece, tendem a adquirir excepcional peso relativo. Como o próprio Oliveiros esclarece na introdução de seu livro, "ao estabelecer que o Estado, a Federação e os militares são as dramatis personae", seu objetivo não foi criar figuras do espírito ou literárias, mas sim buscar as conexões que unem alguns fatos e trabalhar "para que a história possa ter um sentido".

Mais que apontar a oposição constante entre União e Federação, entre poder central e localismos, tópos bastante conhecido em nossa historiografia, Oliveiros quer "estabelecer as condições que permitiram que a Federação se constituísse em pólo antagônico do Estado e as formas que assumiu a relação entre o Estado e a Sociedade". Dialogando com Oliveira Vianna, com juristas e constitucionalistas, com teóricos do Estado, estrategistas militares e líderes civis (como, por exemplo, Armando de Salles Oliveira), passando em revista os momentos mais emblemáticos do processo político nacional, procura dar consistência à sua interpretação de que a história só pode ser compreendida se se compreenderem os elos e as conexões de sentido entre as ações dos diferentes personagens nos diferentes momentos históricos.

De sua parte, não há qualquer mistificação teleológica desta idéia de "sentido", somente a preocupação em "verificar quais são os fatores reais de poder, os grupos sociais organizados que estão presentes ao longo da História do País e ver como interagem", com o que será possível estabelecer “o sentido das mudanças e se em conseqüência delas houve ou não alterações profundas na sociedade" (p. 4). Se o Estado é uma "abstração que faz História", a melhor maneira de compreendê-lo é levando em conta suas encarnações, suas Constituições, que lhe dão maior materialidade e o impelem a agir e a ser considerado. Do mesmo modo, não há como desprezar os dados da morfologia social, as "servidões da infra-estrutura", isto é, "a existência ou não de vias de comunicação capazes de permitir que os diferentes grupamentos populacionais mantenham contatos entre si". $\mathrm{Na}$ ausência de maior "densidade material", ou seja, precisamente destas vias de comunicação, os elementos comuns que se distribuem pelo território ficam como que entregues à própria sorte, sem condições de se "verem como parte de um mesmo projeto de destino", despojados do "pathos que marca as empreitadas humanas de valor" (p. 7). 
A história nacional afirmou-se, assim, sem que se materializasse uma sociedade propriamente dita. Donde o efeito principal: "não havendo Sociedade que se constituísse em objeto negatório do Estado na relação que necessariamente se estabelece entre ambos, o Estado teve como objeto de sua ação as sociedades menores que se organizavam em distantes pontos da colônia, sem quase nenhuma comunicação entre elas". O Estado não teve como deitar raízes na sociedade: não chegou a ser propriamente "amado" e pôde até mesmo não ser temido (pp. 8-9). No século XIX, por exemplo, e mesmo em parte expressiva do XX, tão frágil foi a idéia de Estado que tinha a sociedade que foi fácil à Força Armada "julgar ser um corpo distinto da sociedade política, único a cuidar da defesa do Estado, podendo por isso mesmo orientar-se por suas próprias leis" (p. 59). Os militares foram assim ganhando progressivamente a forma de "uma Nação dentro da Nação", expressão que Oliveiros retira do escritor francês Alfred de Vigny (1797-1863). Não para funcionar como um "Poder Moderador" que interviria nas crises políticas para "resolvê-las de acordo com o disposto na Constituição", mas sim para agir como atores com objetivos próprios. Gradativamente, tomaram consciência "de que os políticos não eram capazes de realizar os ideais pelos quais a Força Armada havia lutado desde 1930" (pp. 6364). Em 1964, finalmente, o Exército foi ao poder.

Observando a história brasileira a partir deste ângulo, Oliveiros Ferreira é levado inevitavelmente a destacar o momento da unidade, ou da falta dela, bem como os personagens que dela buscaram fazer sua causa, ou sua obsessão. Todo e qualquer projeto de nação, entre nós, esteve sempre ameaçado, se é que não inviabilizado, pelo privatismo visceral, incontido e irrefreável, produto natural do tipo de colonização que se efetivou no Brasil, sempre incentivador de um desejo incontido de autonomia por parte dos senhores do poder privado, "os quais construíam, em seu pequeno espaço, a sua visão de destino", o seu projeto de "pequena Pátria". A Monarquia conseguiu lançar os fundamentos da idéia de Estado, mas não teve como se impor sem o concurso ativo dos militares: "Durante todo o Segundo Reinado, para não dizer todo o Império, foi o Exército que garantiu, nos momentos de erupção dos privatismos, a unidade territorial, condição sine qua non para a existência do Estado". Na falta de bom entendimento entre Exército e Estado, como ocorre em
1889, por exemplo, o poder privado (a Federação) terminaria por triunfar. Vinda do século XIX, a tendência se constituiu em eixo da vida republicana.

Oliveiros eleva sua tese à condição de fator explicativo básico. Há um longo parágrafo em Elos partidos que evidencia o eixo mesmo de seu argumento:

Os militares entram em cena logo no primeiro ato de nosso drama, isto é, da história do Brasil enquanto Estado ou projeto dele: 1821 . Nela permanecem como um dos atores principais até 1975 , ano da demissão do general Ednardo D’Ávila Mello do comando do II Exército, em São Paulo, subseqüentemente à morte de Vladimir Herzog, mas o relevo do papel que desempenhavam era menor a partir de 1969 com a edição do Ato Institucional n. 17. Não deixaram a cena mais cedo por causa dos escrúpulos do general-presidente Emílio Garrastazu Médici em candidatar-se, em 1974, à reeleição, abrindo assim caminho para o governo Geisel ao fim do qual o pano cai, em dezembro de 1978. No novo governo, já são atores secundários, ainda que tenha havido um grupo deles que, imaginando estar representando uma commedia dell'arte, aquelas em que não há texto nem direção, invadiu, em $1^{\circ}$ de maio de 1981, o Riocentro e criou para o presidente João Batista Figueiredo, por meio de um atentado malogrado que visava incriminar a esquerda, situações constrangedoras e de difícil solução, mas que indicaram o fim do processo de intervenção militar na vida política do país (p. 49).

Mesmo quando deixaram de agir abertamente como protagonistas, os militares ocuparam o centro das crises políticas, condicionando seus desfechos. Foram decisivos na vida brasileira durante praticamente todo o longo período que se estende de 1821 a 1975. Submeteram-se administrativamente aos governos, como instrumento do Estado, mas; em termos políticos deu-se precisamente o contrário: "foram os governos que dependeram deles para continuar no poder" (p. 51). Operaram não somente como fator de unificação territorial e modelagem do Estado, mas também como alavancas de desenvolvimento. Plasmaram um modo de pensar a nação, o Estado, a sociedade, a política, a gestão. Não se tratou, porém, de um caminho coberto de glórias, vitórias e frutos positivos. Houve efeitos não desejados, escolhas equivocadas, obstáculos imprevistos. Ainda que lançados para esta posição pela incompetência e desorganização das elites civis, acabaram por prolongar a infantilidade política delas. Além do mais, não conseguiram resolver o 
enigma que os catapultou para o primeiro plano, ou seja, não criaram as condições nem para que o Estado se racionalizasse democraticamente, nem para que os "vazios" políticos se preenchessem de modo estável e duradouro.

Oliveiros S. Ferreira deseja que se reflita por que também fracassaram os militares, em que pese a extraordinária força política que armazenaram ao longo do tempo?

Ao menos parte da resposta pode ser encontrada nos encontros e desencontros que se registraram nas relações entre Exército, Estado e Federação. Houve desunião e fraqueza por toda parte. Também os militares não conseguiram progredir de modo unitário e mediante projetos articulados em escala efetivamente hegemônica. O sistema militar se fraturou. Sua vertente propriamente técnica e administrativa - o "Estabelecimento Militar", mais insulado, burocrático, zeloso de regimentos e hierarquias nem sempre conseguiu conviver com o "Partido Fardado", a vertente política e intelectual das Forças Armadas, mais ágil e aberta para interagir com a sociedade e, em momentos críticos, liderar a insatisfação social em nome de um "projeto nacional".

A questão, portanto, não se esgota no mero registro do protagonismo militar, mas exige que também se avaliem as conseqüências da tensão recorrente entre Estabelecimento Militar, Partido Fardado e elites civis. Enquanto os anéis entre estes segmentos - mais precisamente, entre União, Federação e militares - puderam permanecer entrelaçados, articulando setores civis a amplos setores militares e ao Partido Fardado, foi possível à União "pôr em prática políticas dirigidas para o futuro” (p. 591). Rompidos os elos, tudo se complicou. A União perdeu seu "partido" e os militares recolheram-se ao Estabelecimento e muitas vezes aos porões, de onde praticarão os excessos, os arbítrios e as violências que tipificam sua performance na história republicana do país. Para complicar, a Federação perdeu importância progressiva, graças ao avanço da crise fiscal que também corroeu a União. Tudo contribuiu para que os elos se soltassem. Elos partidos.

Poder-se-ia imaginar que o analista, assim posto o problema, concluiria pela constatação de que o Partido Fardado carregaria em si mesmo, sem mais, por sua própria existência, o futuro nacional nas mãos, que ele seria, no fundo, mais vítima do que culpado, já que impossibilitado de cumprir sua vocação. Não se encontrará tal conclusão no livro de Oliveiros S. Ferreira, e nem mesmo no conjunto de sua obra. Há, é verdade, certo tom de lamento em algumas de suas linhas, desejosas de que outros tivessem sido os fatos e as escolhas. O Partido Fardado jamais teve como se manter unido e em ação virtuosa. Sentiu os efeitos da fragmentação que atingiu o cerne do próprio Exército, separando-o em facções "nacionalistas", de "esquerda"; e facções defensoras da Ordem a qualquer custo. A avalanche fundamentalista e fanática da idéia do Movimento Comunista Internacional como inimigo externo a ser combatido invadiu o Partido Fardado, impondo-lhe sua maior tragédia.

"O drama do Partido Fardado, que em certo sentido é o drama do Brasil, é que na defesa da Ordem - defesa levada à extremidade lógica, como se fora numa operação militar - ele cedeu, depois de 1935, à imagem que parte do mundo civil construiu do que seria a ameaça do comunismo ao 'orbe católico’ e sua Ordem” (p. 583).

Houve também a força objetiva das mudanças sociopolíticas e culturais - "as profundas transformações que se dão nos costumes femininos com a descoberta da pílula anticoncepcional e o movimento de liberação feminina nos anos 1960; o prestígio que a Teologia da Libertação começa a ter junto às populações que vivem na periferia e a crise de identidade da Igreja Católica depois do Concílio Vaticano II" -, que, pouco a pouco, criaram a sensação de que tudo o que dava esteio à Ordem (a propriedade, a família, a religião) estava sob ameaça, incentivando o irracionalismo apocalíptico do "crepúsculo dos deuses wagneriano” (pp. 584-585). Compreenderse-ia bem a imensidão da tragédia, segundo Oliveiros, se não se esquecesse "que os membros do Partido Fardado foram criados no culto dos valores associados a essas idéias-chave", ou seja, tinham eles também seus limites e bloqueios ideológicos.

É um modo de se interpretar a história da República. Polêmico, controvertido, discutível, mas de maneira alguma desprovido de sentido e coerência. Oliveiros Ferreira pode não resolver todos os problemas a que se propôs, mas é inegável que nos fornece um minucioso e abrangente mapa para isso. Sua visão de conjunto é otimista, apaixonada e repleta de densidade cívica, a ponto de levá-lo a afirmar - contrariamente às interpretações convencionais - "que os períodos de vivência democrática foram maiores do que aqueles de negação das liberdades, e que até mesmo os anos daquilo que 
denominei de 'a longa noite hobbesiana' significaram, cada qual à sua maneira, momentos históricos em que se lançaram as bases para progressos que de outra forma demorariam mais tempo para consolidar-se como realidade e tornar-se coisa comum na consciência coletiva" ( $\mathrm{p}$. XIV).

Coerente até o fim, seu livro conclui com uma ponta confessa de pessimismo. Feridos de morte ou desarticulados o Partido Fardado, a União e a Federação,

[...] sobraram as personalidades, mas não havendo estruturas que impulsionem o processo social, a Política feneceu. O Mercado, novo deus fenício a cobrar sacrifícios, impôs-se como senhor de baraço e cutelo. Como dizia alguém, quando não há política, há pornografia. $\mathrm{Ou}$, parafraseando outrem, aristocrata e mais polido, poderia dizer que, tendo desaparecido a Grande Política, as Idéias, discutem-se as pessoas. Quando possível (p. 591).

Salvo melhor juízo, é precisamente onde nos encontramos. Vinte e dois anos depois da redemocratização, ainda falta ao Brasil a solução de seu enigma fundacional, o da organização autônoma da sociedade, bem como o da reposição em novas e duradouras bases dos elos entre estrutura jurídico-político-administrativa (União, Federação, sistema político) e mundo da vida social, entre Estado e sociedade. Continuamos sem sujeitos capazes de promover "políticas dirigidas para o futuro" e seguramente sem projetos nacionais. Talvez o capitalismo globalizado e informacional, a modernidade líquida e radicalizada que celebra o ingresso dos humanos no século XXI, impeça que se continue a pensar em termos de sujeitos e projetos nacionais. Esta é uma questão categoricamente em aberto. Se provocado, Oliveiros Ferreira diria que o momento requer o amadurecimento de novos "revolucionários da Ordem", ao estilo do que imaginaram certas traduções do Partido Fardado. Pode não ser a melhor perspectiva, a via mais plausível e factível, mas não deixa de ser uma perspectiva.

\footnotetext{
MARCO AURÉLIO NOGUEIRA é professor titular de Teoria Política da Faculdade de Ciências e Letras da Universidade Estadual Paulista (Unesp), campus de Araraquara, SP. E-mail: nogueira@fclar.br.
}

\section{A dureza (e a ternura) do essencialismo político}

Armando BOITO Jr. Estado, politica e classes sociais. São Paulo, Edunesp, 2007. 271 páginas.

\section{Cicero Araujo}

Este livro de Armando Boito Jr. deve causar certo desconcerto ao leitor. Embora anuncie, logo no início, que sua "ambição maior" é contribuir para "a renovação da teoria marxista", é um tanto difícil discernir o que há de fato renovador na coletânea de ensaios que reuniu no livro. Não que isso o torne desinteressante: em sua própria reiteração de idéias desgastadas, há algo de engenhoso no texto. O desconcerto talvez seja causado também pelo estilo: fórmulas duras são defendidas com incrível serenidade, que às vezes até deixam escapar locuções do tipo "nos parece que", "não acredito que", "não é nossa convicção" - como se fossem um cumprimento aos leitores indispostos, os quais o autor provavelmente saiba não serão poucos. As críticas que seguem, aliás, não tem pretensão de novidade; no entanto, como o livro não registra sua existência, será preciso insistir nelas aqui.

O volume está dividido em duas partes. A primeira trata de questões abrangentes da teoria política marxista: o Estado, a transição entre tipos de Estado, suas relações com o modo de produção e as classes sociais, as revoluções e o socialismo. A segunda concentra-se no mundo do trabalho, suas mutações (ou não), a organização sindical e política das classes trabalhadoras, o conceito de cidadania nesse contexto e, novamente (mas agora com um olhar para o futuro), o socialismo e a revolução. O pressuposto das duas partes parece ser a idéia de modo de produção como uma totalidade social, "não se atendo, portanto, apenas ao nível econômico". Isso leva o autor a pensar cada modo de produção como composto de dois níveis integrados: de um lado, as forças produtivas e as relações de produção e, de outro, o Estado ("a estrutura jurídico-política"). De forma que, por exemplo, o capitalismo como modo de produção não é apenas a economia, mas o Estado "capitalista" ou "burguês", com ambos os níveis se "determinando" e "sobredeterminando" um ao outro; o mesmo 